IRA-International Journal of Applied Sciences ISSN 2455-4499; Vol.04, Issue 02 (2016)

Institute of Research Advances

Pg. no. 230-236

http://research-advances.org/index.php/IRAJAS

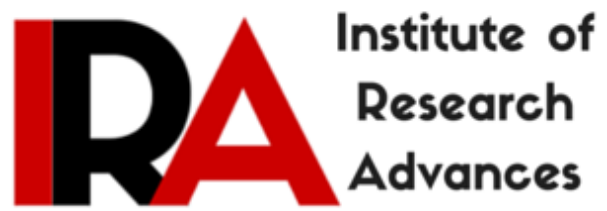

\title{
Impedance spectroscopy and structural analysis of VO2+ doped Poly vinyl chloride (PVC) electrolytes
}

${ }^{1}$ K. Bhagyasree, ${ }^{2}$ Y.Madhava Kumar, ${ }^{3}$ N.O. Gopal, ${ }^{4}$ Ch.Ramu

$\mathbf{1 , 2 , 3 , 4}$ Department of Physics, Vikrama Simhapuri University PG Centre, Kavali 524201, India.

Type of Review: Peer reviewed.

DOI: http://dx.doi.org/10.21013/jas.v4.n2.p3

\section{How to cite this paper:}

Bhagyasree, K., Kumar, Y., Gopal, N., \& Ramu, C. (2016). Impedance spectroscopy and structural analysis of $\mathrm{VO} 2+$ doped Poly vinyl chloride (PVC) electrolytes. IRAInternational Journal of Applied Sciences (ISSN 2455-4499), 4(2), 230-236. doi:http://dx.doi.org/10.21013/jas.v4.n2.p3

(C) Institute of Research Advances

\section{(cc) EY-NC}

This work is licensed under a Creative Commons Attribution-Non Commercial 4.0 International License subject to proper citation to the publication source of the work.

Disclaimer: The scholarly papers as reviewed and published by the Institute of Research Advances (IRA) are the views and opinions of their respective authors and are not the views or opinions of the IRA. The IRA disclaims of any harm or loss caused due to the published content to any party. 


\section{ABSTRACT}

This paper reports on structural, morphological and electrical properties of solid polymer electrolyte films based on PVC complexed with different concentrations of $\mathrm{VO}^{2+}$ using solution cast technique. The films were characterized by X-ray diffraction (XRD), scanning electron microscopy (SEM) and impedance spectroscopy studies. $X$ - ray diffraction $(X R D)$ results revealed that the amorphous nature of $P V C$ polymer matrix increased with the increase of $\mathrm{VO}^{2+}$ ions concentration. The electrical conductivity was evaluated from impedance spectroscopy studies in the temperature range $303-373 \mathrm{~K}$ and the conductivity was found to increase with increasing dopant concentration. The polymer complexes exhibited Arrhenius type dependence of conductivity with temperature. The variation in film morphology was examined by scanning electron microscopy (SEM).

\section{Introduction:}

Solid polymer electrolytes (SPE) has attracted considerable attention in terms of its scientific importance and application in energy storage or conversion devices such as batteries, fuel cells, super capacitors etc., arising from its high ionic conductivity, electrochemical stability and good mechanical properties [1-2]. Apart from lithium salt complexes, some other electrolytes were also reported containing salts of sodium, magnesium and zinc metals [3-5]. Presently the world wide attention has focused on the high performance and environment friendly nature of energy storage devices. Lithium ion conducting polymer electrolytes are incorporated in most of the commercially available batteries for their fabrication due to its high capacity and excellent chemical stability. At the same time, lithium ion batteries are relatively expensive and suffer from safety limitations because of its explosive nature. Polyvinyl chloride (PVC) is one of the most important commercial polymers that has wide range of applications. PVC is a linear, thermoplastic, substantially amorphous polymer, with a huge commercial interest due to the accessibility to basic raw materials and to its properties. It is used as thermoplastic due to its many valuable properties like low price, good process ability, chemical resistance, good mechanical strength, thermal stability and low flammability. Currently, PVC is one of the world's leading synthetic polymers with global consumption of approximately 40 million tonnes per annum $[6,7]$.

Among the transition metal ions, $\mathrm{VO}^{2+}$ ion has been extensively used as a probe to study the symmetry of the crystalline electric field. Vanadium oxides have also shown promise as optical switching materials on the basis of their electro-chromic properties [8-11]. The properties of theVO ${ }^{2+}$ doped PVC polymer films have been reported in this paper.

\section{Experimental}

Poly vinyl chloride (PVC) obtained from M/S Sigma Aldrich has a mean relative molecular mass of about $534,000 \mathrm{~g} / \mathrm{mol}$. PVC polymer films doped with $\mathrm{VOSO}_{4}$ in various concentrations were prepared at room temperature by solution casting method. The desired concentration of $\operatorname{VOSO}_{4}$ solutions $(1,2,3,4$ and $5 \%$ ) were prepared by using distilled water. $1 \mathrm{~g} / \mathrm{mol}$ of PVC polymer is dissolved in tetra hydro furan (THF) separately. Different amounts of $\mathrm{VOSO}_{4}$ solution $(1,2,3,4$ and $5 \mathrm{~mol} \%$ ) were added into the polymer solution. The mixture was magnetically stirred for 10-12 hours to get homogeneous mixture and then cast onto glass dishes. The film was slowly evaporated at room temperature to obtain free standing polymer film at the bottom of the dishes.

In order to investigate the nature of the polymer electrolytes, the electrical properties of the polymer electrolyte films were measured by a computer controlled impedance analyzer (Aglient E4980 precision LCR meter, USA) over the frequency range $20 \mathrm{~Hz}-2 \mathrm{MHz}$ with a signal level of $10 \mathrm{mV}$. The measurements were carried out by sandwiching the polymer electrolyte film between two stainless steel electrodes in the temperature range of $303-373 \mathrm{~K}$. X-ray diffraction measurements were carried out using a BRUKER D8 ADVANCE diffractometer with $\mathrm{CuK \alpha}$ radiation (1.5406 ̊). The films were 
scanned at $2 \theta$ angles between $10^{\circ}$ and $80^{\circ}$ with a step size of $0.02^{\circ}$. The morphology of the polymer films was characterized by the JEOL JSM 840A electron microscope (SEM) with scanning attachment.

\section{Results \& Discussion:}

\section{Impedance analysis:}

In solid state ionic batteries, the polymer electrolytes work as a separator as well as medium to transport ions from anode to cathode. Hence, ionic conductivity of polymer electrolyte is a very important parameter for battery applications. Figure 1 shows the impedance spectra of PVC doped with different concentrations of $\mathrm{VO}^{2+}$ based polymer electrolytes at room temperature. Typical AC impedance plot shows two well - defined regions: (1) depressed semi-circle at high frequency side and (2) inclined line at low frequency side. In PVC: $\mathrm{VO}^{2+}$, the depressed semicircle, observed in the high-frequency region at $2-$ $5 \mathrm{~mol} \%$ of $\mathrm{VO}^{2+}$ is due to the bulk effect of the electrolytes and the linear region in the low-frequency range is attributed to the effect of the blocking electrodes [12]. The disappearance of high frequency semicircular portion leads to a conclusion that the current carriers are ions and hence the total conductivity is mainly the result of ion conduction. The bulk resistance $\left(\mathrm{R}_{\mathrm{b}}\right)$ can be retrieved from the intercept of high frequency semi-circle or the low frequency spike on the $Z^{\prime}$ - axis [13]. The ionic conductivity values of the electrolytes are calculated by using the equation:

$$
\sigma=\frac{d}{R_{b} A}
$$

Where, $d$ and $A$ are the thickness and known area of the electrolyte film respectively and $R_{b}$ is the bulk resistance of the electrolyte film. From the figure, it is seen that the conductivity of pure PVC is about $4.87 \times 10^{-8} \mathrm{Scm}^{-1}$ at room temperature and the highest conductivity has been found to be $2.68 \times 10^{-6} \mathrm{Scm}^{-1}$ at room temperature for PVC-5 mol\% $\mathrm{VO}^{2+}$ polymer electrolyte. The increase in ionic conductivity with the addition of $\mathrm{VO}^{2+}$ is attributed to a reduction in crystallinity of copolymer electrolyte and also the increase in number of mobile charge carriers. The coordination interactions of the ether oxygen atoms of $\mathrm{PVC}$ with $\mathrm{VO}^{2+}$ cations, which result in a reduction in crystallinity of PVC copolymer, are responsible for the increase in ionic conductivity.

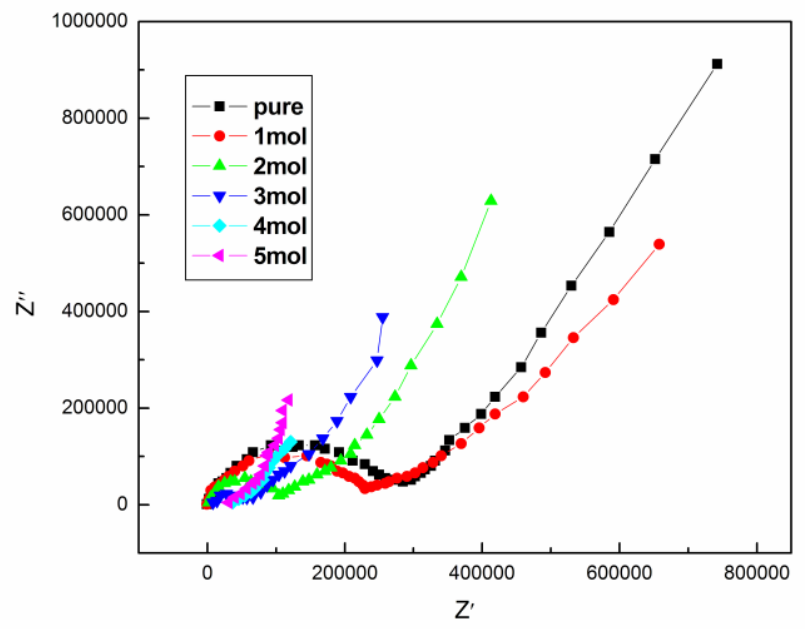

Figure 1: Room-temperature Nyquist impedance plots of $\mathrm{VO}^{2+}$ ions doped PVC polymer electrolyte films. 


\section{Concentration dependence of conductivity:}

The conductivity at room temperature of the pure PVC is found to be $4.87 \times 10^{-8} \mathrm{Scm}^{-1}$. This study shows that the addition of $\mathrm{VO}^{2+}$ ions increases the ionic conductivity of PVC. Figure 2 shows that the variation of ionic conductivity of PVC: $\mathrm{VO}^{2+}$ polymer electrolyte system with different concentration of $\mathrm{VO}^{2+}$ ions. The spectra show that the conductivity increases with an increase in concentration. The initial increase in conductivity is due to the availability of free mobile ions [14].

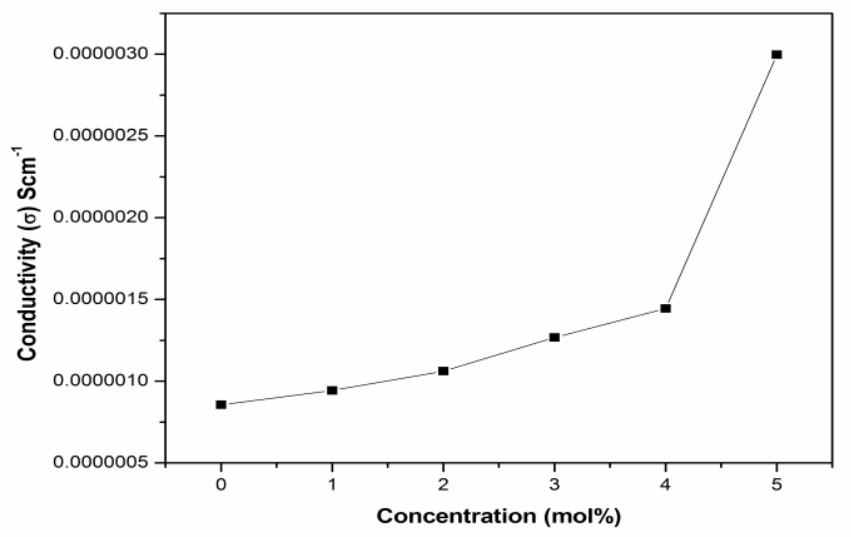

Figure 2: Room-temperature ionic conductivity as a function of $\mathrm{VO}^{2+}$ concentration for the PVC polymer electrolyte system.

\section{Temperature dependence conductivity:}

The solid polymer electrolytes follow Arrhenius as well as Vogel-Tamman-Fulcher (VTF) types of ionic conduction which depends on the type of the salt, polymer and the temperature range [15]. Figure 3 represent the temperature dependence of ionic conductivity for all compositions of $\mathrm{PVC}_{\mathrm{VO}} \mathrm{VO}^{2+}$ systems. From the plot it has been observed that as temperature increases the conductivity values also increases for all the compositions. The experimental data indicate that the ionic conductivity is enhanced with increasing temperature at high salt concentration. When the temperature is increased, the mobility of polymer chain is enhanced, and the fraction of free volume in the polymer electrolyte system increases accordingly, which facilitates the transitional motion of ions [16]. Thus the segmental motion either allows the ions to hop from one site to other site, or it provides pathway for ions to move, which leads to an increase in ionic conductivity of the polymer electrolyte.

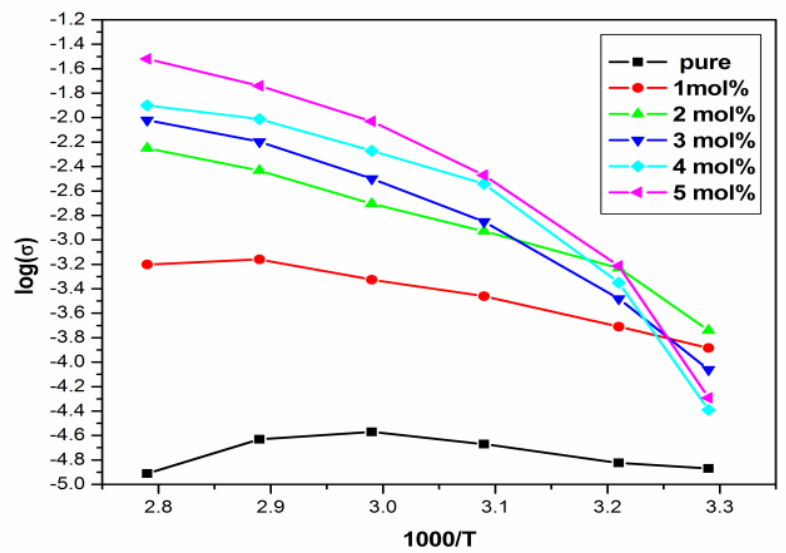

Figure 3: Nyquist impedance plots of the polymer electrolyte film with $\mathrm{VO}^{2+}$ at different temperatures. 


\section{X-ray diffraction studies}

$\mathrm{XRD}$ analysis is very useful in determining the structure of the polymer electrolytes. Figure 4 represents the X-ray diffraction of pure and doped PVC polymer electrolyes with different concentrations of $\mathrm{VO}^{2+}$. For pure PVC a broad peak was observed at $2 \theta$ region of $11-18^{\circ}$ which can be attributed to the amorphous nature of pure PVC. This peak is broadened and its relative intensity decreases with increase of $\mathrm{VO}^{2+}$ concentration, which indicates the increase in the amorphous nature of the host polymer. The increase in the amorphous nature causes a reduction in the energy barrier to the segmental motion of the polymer electrolyte. This amorphous nature results in greater ionic diffusivity and high ionic conductivity, which can be observed in amorphous polymers having flexible back-bone $[17,18]$.

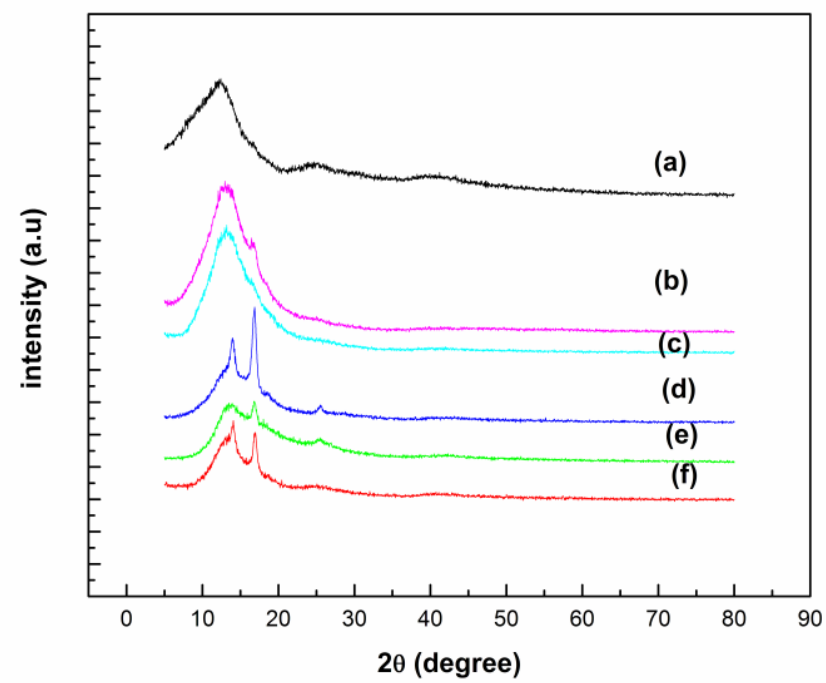

Figure 4: XRD patterns of PVC polymer films containing $\mathrm{VO}^{2+}$ (a) pure (b) $1 \mathrm{~mol} \% \quad$ (c) $2 \mathrm{~mol} \%$ (d) $3 \mathrm{~mol} \%$ (e) $4 \mathrm{~mol} \%$ (f) $5 \mathrm{~mol} \%$

\section{Scanning electron microscopy analysis}

SEM images of pure and $\mathrm{VO}^{2+}$ doped polymer electrolytes are shown in Figure 5(a-f) respectively. Small craters are observed on the SEM images, formed due to evaporation of the solvent during preparation of the thin film [19]. It can be observed by comparing Figure 5(a-f) that the pore size of 5 mol\% of $\mathrm{VO}^{2+}$ doped $\mathrm{PVC}$ is much smaller and its pore surface distribution is better than that of other polymer electrolytes. Compared to the other polymer electrolytes, $5 \mathrm{~mol} \%$ of $\mathrm{VO}^{2+}$ doped $\mathrm{PVC}$ has the highest ionic conductivity and shows less phase separation, more homogeneity, indicating that the polymer and salt are completely dissolved. It can be inferred that when the molar ratio of dopant concentration is high in the polymer matrix an agglomeration of dopant takes place. Therefore, phase separation takes place in this polymer electrolyte system. As a result, the charge carriers are transported very slowly in the presence of blocking phase leading to decrease in ionic conductivity $[20,21]$ in 1 to 4 mol\% of $\mathrm{VO}^{2+}$ doped PVC films. 

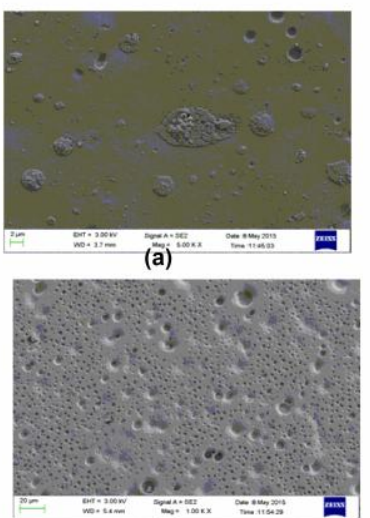

(c)

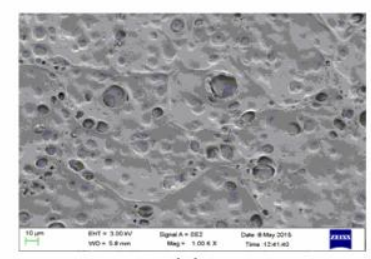

(e)

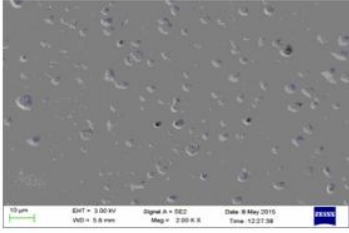

(b)

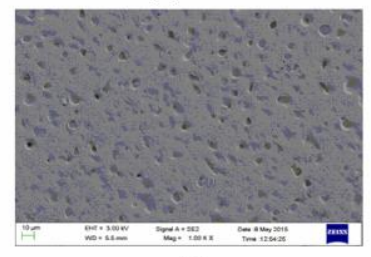

(d)

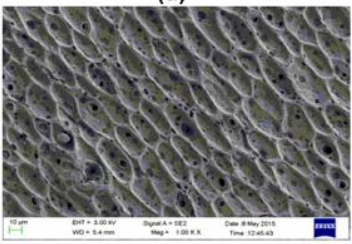

(f)

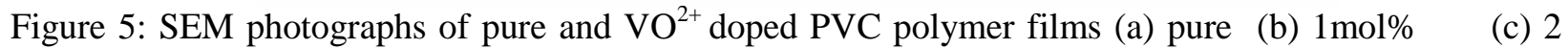
mol\% (d) $3 \mathrm{~mol} \%$ (e) $4 \mathrm{~mol} \%$ (f) $5 \mathrm{~mol} \%$

\section{Conclusion:}

In summary, Solid polymer electrolytes based on poly (vinyl chloride) (PVC) doped with $\mathrm{VO}^{2+}$ at different concentration were prepared using solution cast technique and it could be concluded that the structural, morphological and electrical properties of PVC polymer electrolyte films can be influenced by complexing it with $\mathrm{VO}^{2+}$. X- ray diffraction (XRD) results revealed that the amorphous nature of PVC polymer matrix increased with the increase of $\mathrm{VO}^{2+}$ ions concentration. Electrical conductivity was measured with an $\mathrm{AC}$ impedance analyzer in the frequency and temperature range $1 \mathrm{~Hz}-1 \mathrm{MHz}$ and 303 $\mathrm{K}-373 \mathrm{~K}$ respectively. The conductivity of pure PVC is about $4.87 \times 10^{-8} \mathrm{Scm}^{-1}$ at room temperature and the highest conductivity has been found to be $2.68 \times 10^{-6} \mathrm{Scm}^{-1}$ at room temperature for PVC-5 mol\% $\mathrm{VO}^{2+}$ polymer electrolyte. The increase in ionic conductivity with the addition of $\mathrm{VO}^{2+}$ is attributed to a reduction in crystallinity of copolymer electrolyte and also the increase in number of mobile charge carriers.

\section{Acknowledgments:}

The authors thank Dr. Tushar Jana, Associate Professor, Dept.of Chemistry, for his constant encouragement and active co-operation in carrying out the work. We also thank to Network Resource Centre in Central University of Hyderabad for providing the facilities to carry out experimental work.

\section{References:}

1. Appetecchi GB, Scrosati B. 2004 Electrochimica Acta 39:2187.

2. Stephan M,2000. Eur Polym J 42:21.

3. Patrick A, Glasse M, Latham R, Linford R 1986. Solid state ionics 18-19,1063.

4. Groce f, Gerace F, Dautzember G, Passerini S, Appetecchi GB, Scrosati B. 2004 Electrochimica Acta 39:2187.

5. Stephan M,2000. Eur Polym J 42:21. 
6. Warren. H, 2015 World Petrochemical Conference. Proceedings. Houston: IHS Chemical, 2015; 479-503

7. Azman Hassain, Barry Haworth, J. Materials Processing Technology 172 (2006) 341.

8. M. S. Dahiya, S. Khasa, A. Agarwal, Journal of Thermal Analysis and Calorimetry (2016) 123 (1) 457-465.

9. Deen Gu', Zhanhong Sun, Xin Zhou, Rui Guo, Tao Wang, Yadong Jiang Applied Surface Science (2015) 359, 819-825

10. S. Loquai, B. Baloukas, O. Zabeida, J.E. Klemberg-Sapieha, L. Martinu Solar Energy Materials and Solar Cells (2016) 155, 60-69.

11. L. Zeng, T.S. Zhao' L. Wei Y.K. Zeng, Z.H. Zhang Journal of Power Sources (2016) 327 374-383

12. Selvasekarapandian S, Baskaran R and Hema M, (2005) Physica B, 357, 412.

13. Ramya C S, Selvasekarapandian S, Savitha T, Hirankumar G, Baskaran R, Bhuvaneswari M S and Angelo P C, (2006) Eur Polym J., 42(10), 2672.

14. M. Hema, S. Selvasekerapandian, A. Sakunthala, D. Arunkumar, H. Nithya (2008) Physica B. 4032740.

15. Baskaran R, Selvasekarapandian S, Kuwata N, Kawamura J, Hattori T, (2007) J Phys Chem Solids, 68(3), 407.

16. Baskaran R, Selvasekarapandian S, Kuwata N, Kawamura J and Hattori T, (2006) Solid State Ionics, , 177(26-32), 2679.

17. Morita M, Araki F, Yoshimoto N, Ishikawa M and Tsutsumi H (2000) Solid State Ionics 136 1167

18. Baskaran R and Sevasekarapadian S, (2004) Ionics 10129.

19. Manuel Stephan A, Premkumar T, Renganathan N G, Pitchumani S, Thirunakaran R \& Muniyandi N, (2000) J Power Sources, 8980.

20. Ramesh S, Liew C W, Morris E \& Durairaj R, (2010) Thermochim Acta, 511140.

21. Stephan A M, Saito Y, Muniyandi N, Renganathan N G, Kalyanasundaram S \& Elizabeth R N, Solid State Ionics, 148 (2002) 467. 